\title{
The Genetic Variant c.553G > T in the Lipoprotein A5 Effects on Lipid Profile Parameters Levels
}

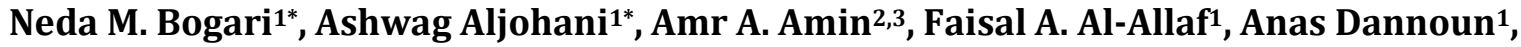 \\ Mohiuddin M. Taher ${ }^{1,4}$, Atalla Elsayed ${ }^{5,6}$, Dareen Ibrahim Rednah7, Osama Elkhatee ${ }^{8}$, \\ Massimo Porqueddu' ${ }^{9}$, Francesco Alamanni' ${ }^{10}$, Ahmed Fawzy ${ }^{11^{*}}$

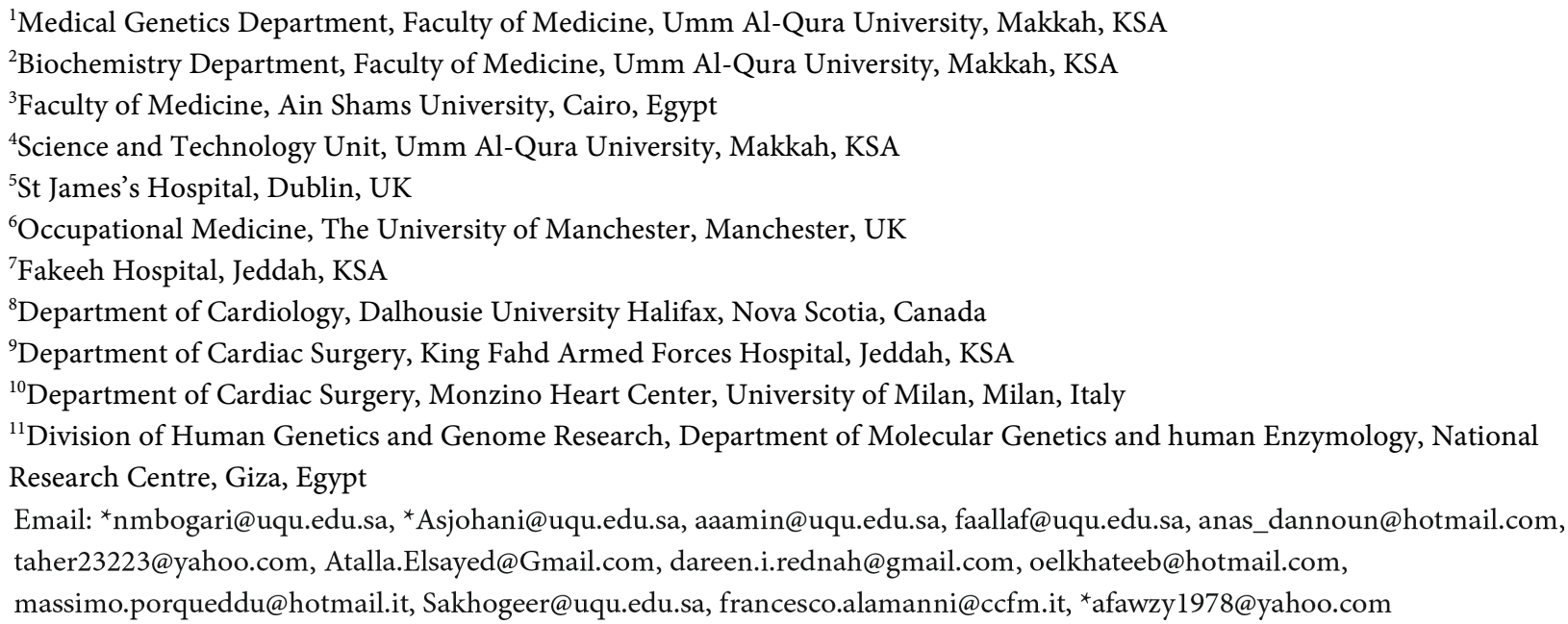

How to cite this paper: Bogari, N.M., Aljohani, A., Amin, A.A., Al-Allaf, F.A., Dannoun, A., Taher, M.M., Elsayed, A., Rednah, D.I., Elkhatee, O., Porqueddu, M., Alamanni, F. and Fawzy, A. (2019) The Genetic Variant c.553G $>\mathrm{T}$ in the Lipoprotein A5 Effects on Lipid Profile Parameters Levels. World Journal of Cardiovascular Diseases, 9, 122-131.

https://doi.org/10.4236/wjcd.2019.92012

Received: January 23, 2019

Accepted: February 17, 2019

Published: February 20, 2019

Copyright $\odot 2019$ by author(s) and Scientific Research Publishing Inc. This work is licensed under the Creative Commons Attribution International License (CC BY 4.0).

\begin{abstract}
Abnormal levels of plasma lipid have been linked to atherosclerosis, strokes and heart conditions. Variations in high-density lipoprotein (HDL) and low-density lipoprotein (LDL) cholesterol levels are considered as risk factors for coronary artery disease (CAD). Furthermore, triglycerides are a leading cause of cardiovascular disease. Therefore, measurement of plasma lipid levels is an important mortality predictor. Several factors were associated with irregularity in plasma lipids such as genetic alterations. Recent researches have linked single nucleotides polymorphism (SNP) in ApoA5 gene with these deviations. In this study, we reported the effects of the genetic variant c.553G $>\mathrm{T}$ in ApoA5 on the levels of plasma lipids. To explore these effects, a case-control study including 280 male and female subjects (44 of them were assigned as $\mathrm{CAD}$ cases while the remaining subjects were categorized as control) was established. All patients in the study were recruited from the western region in KSA. The results have detected minor variations in LDL, HDL
\end{abstract}


http://creativecommons.org/licenses/by/4.0/

Open Access and cholesterol levels between CAD patients carrying $\mathrm{T}$ allele and CAD patients carrying the WT allele. However, there were no significant effects due to these variations. TG levels in the wild type carriers reached up to 291 $\mathrm{mg} / \mathrm{dl}$ while $\mathrm{T}$ allele carriers, the cases, presented lower levels of TG (170 $\mathrm{mg} / \mathrm{dl}$ and $71 \mathrm{mg} / \mathrm{dl}$ ). Although, $\mathrm{T}$ allele showed no effects on plasma lipids with the exception of TG levels. We suggest by this study that $\mathrm{T}$ allele in this SNP might be considered as a valuable tool in the diagnosis of CAD.

\section{Keywords}

APOA5 Gene, Polymorphism, Genetic Variation, Coronary Artery Disease, Kingdom of Saudi Arabia (KSA)

\section{Background}

Although blood lipids play significant roles in the body, they have been associated with various diseases and infections. Lipids levels in the blood could indicate the presence of certain viruses. For instance, human immunodeficiency virus (HIV) causes high density lipoprotein Cholesterol (HDL-C) and total cholesterol (total-C) levels to decrease. A study in India showed a correlation between low levels of HDL-C and giardia and entamoebic parasites [1]. In addition, imbalanced levels of plasma lipids such as triglycerides and cholesterol and lipoproteins including low density lipoprotein (LDL) and high density lipoprotein (HDL) have wildly been associated with numerous diseases. Elevation in cholesterol levels in bloodstream may form plaques in blood vessels which could lead to the development of coronary heart disease or stroke eventually [2]. In the human body, cholesterol is made in the liver and can be good cholesterol or bad cholesterol. A study that was done on applicants of life insurance in the United States showed that the reduction of the good cholesterol or HDL is one of the risk factors that could cause coronary heart disease (CHD). On the other hand, elevation of LDL or the bad cholesterol causes similar outcomes. Therefore, the measurement of LDL and HDL levels is considered as a predicative sign of mortality [3]. Not only do these cholesterol molecules could cause cardiac problems, but also triglycerides which were considered lately as a determinant factor for cardiovascular disease (CVD). A study has shown that rising of triglycerides levels to $2-10 \mathrm{mmol} / \mathrm{L}$ increases the possibility of having CVD while elevation of triglycerides levels to more than $10 \mathrm{mmol} / \mathrm{L}$ increases the chances of developing both of CVD and acute pancreatitis [4]. Coronary artery disease plays a major role in increasing the mortality rate, and it has undeniable effects on the patients' life-style.

Variations in plasma lipids and lipoproteins levels have been correlated with various factors including genetic modifications. Currently, several studies have shown links between a number of ApoA5 polymorphisms, a gene that is located on chromosome 11q23, and changes in plasma lipid parameters' levels [5]. These single nucleotide polymorphisms (SNPs) include but are not limited to $-1131 \mathrm{~T}>\mathrm{C}$ 
for $\mathrm{APOA}^{\star} 2$ and $\mathrm{c} .56 \mathrm{C}>\mathrm{G}(\mathrm{S} 19 \mathrm{~W})$ for $\mathrm{APOA} 5^{\star} 3$ which were proven to alter triglycerides levels [6]. Recent studies have led to the discovery of another variant, c.553G $>\mathrm{T}$, through the sequencing of ApoA5 coding region [7]. This variant was found to increase plasma TG levels which may lead to metabolic syndrome (MS) [8]. In this study we have investigated the influence of c.553G $>\mathrm{T}$ variant on lipid parameters in normal and CAD patients.

\section{Methods}

Peripheral blood samples were withdrawn from CAD patients and control groups, DNA were extracted from the samples by using GeneJET Whole Blood Genomic DNA Purification kit (Thermo Scientific Co. Ltd.). All samples were stored at $-20^{\circ} \mathrm{C}$. Digestion with restriction enzymes and polymerase chain reaction (PCR) were used to determine c.553G>T (rs2075291) genotype of Apoa5 gene. Amplification by PCR was done in Veriti thermal cycler (Life technologies co.) using forward: 5'-AGA CAC CAA GGC CCA GTT GCT GGG '3, Reverse: 5'-ATG CCG CTC ACC AGG CTC TCG GCG ' 3 as primers. Amplification of DNA was performed under specific conditions as follow: denaturation of DNA at $95^{\circ} \mathrm{C}$ for $5 \mathrm{~min}$, amplification of DNA through 37 cycles of $95^{\circ} \mathrm{C}$ for $30 \mathrm{~s}, 58^{\circ} \mathrm{C}$ for $30 \mathrm{~s}$, and $72^{\circ} \mathrm{C}$ for $1 \mathrm{~min}$, and a final extension of DNA at $72^{\circ} \mathrm{C}$ for $10 \mathrm{~min}$. The products of the primers were $138 \mathrm{bp}$ of PCR fragments. Then, $20 \mu \mathrm{l}$ PCR products were added to $5 \mathrm{U}$ of Hae III enzyme (New England BioLabs Inc.) to bring the volume to $25 \mu \mathrm{l}$ followed by an incubation over night at $37^{\circ} \mathrm{C}$. Subsequently, the products were separated using a 3\% agarose gel after digestion with Hae III enzyme, and were visualized using UV light and ethidium bromide. The outcomes were a $138 \mathrm{bp}$ fragment for TT homozygotes, two fragments of 138 and $87 \mathrm{bp}$ for GT heterozygotes and $87 \mathrm{bp}$ fragment for GG homozygotes. See Figure 1.

\section{Results}

\subsection{Baseline Characteristics}

This study included 136 males and 144 females bringing the total number to 280 subjects. Forty-two of the males and 2 of the females are patients with coronary artery disease (CAD), the cases, while 94 males and 115 females were assigned as controls. HAD and LDL levels were obtained from both groups of CAD patients, GG homozygotes CAD patients and CAD patients carrying $\mathrm{T}$ allele, and data analysis were performed (Table 1).

\subsection{Association of T Allele Variant of Apoa5 with LDL and HDL Levels}

The results from analysis showed that there was no significant difference in the good cholesterol or HDL levels between CAD patients carrying the wild type allele and CAD patients with $\mathrm{T}$ allele. HDL levels were found to be lower in CAD patients with $\mathrm{T}$ allele than the other CAD patients group (The averages of HDL 


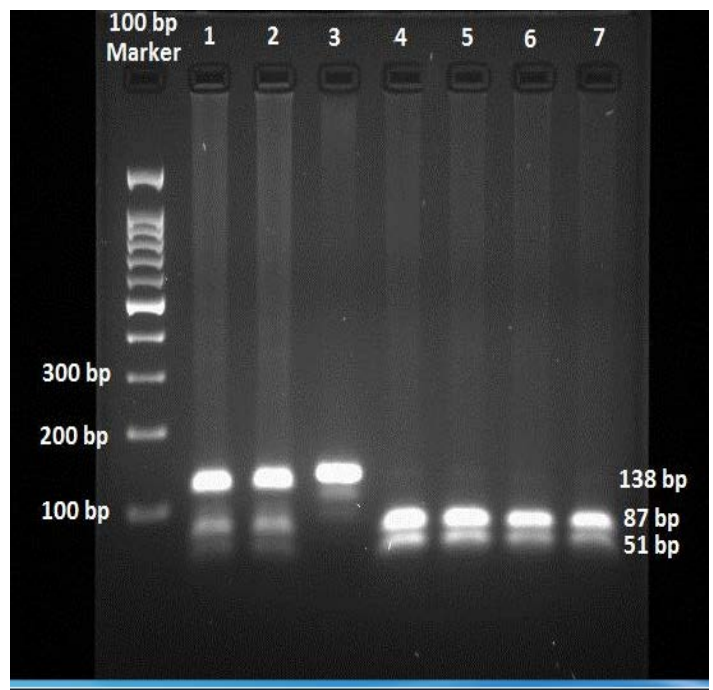

Figure 1. Results from restriction fragment length polymorphism (RFLP) of APOA5 c. $553 \mathrm{G}>\mathrm{T}$ locus. The fragments from samples were stained with ethidium bromide after their separation on a 3\% agarose gel. Lanes 1 and 2 are (GT) heterozygotes and lane 3 is (TT) homozygote; and lanes: 4, 5, 6, 7 are (GG) homozygotes. bp = base pair(s)—one bp corresponds to approximately $3.4 \AA(340 \mathrm{pm})$ of length along the strand, and to roughly 618 or 643 daltons for DNA and RNA respectively. DNA Ladder is designed for sizing and approximate quantification of double-stranded DNA in the range of $100 \mathrm{bp}$ to $2000 \mathrm{bp}$.

Table 1. Baseline characteristics and clinical properties for the participants in this study.

\begin{tabular}{|c|c|c|c|}
\hline & CAD (44) & Control (209) & P-value \\
\hline \multicolumn{4}{|l|}{ Age (year) } \\
\hline Under 20 years & $0=0.0 \%$ & $12=4.7 \%$ & \multirow{6}{*}{0.000} \\
\hline 21 - 30 years & $2=0.8 \%$ & $84=33.2 \%$ & \\
\hline $31-40$ years & $2=0.8 \%$ & $55=21.7 \%$ & \\
\hline $41-50$ years & $7=2.8 \%$ & $25=9.9 \%$ & \\
\hline $51-60$ years & $21=8.3 \%$ & $18=7.1 \%$ & \\
\hline $61-70$ years & $11=4.3 \%$ & $9=3.6 \%$ & \\
\hline More than 70 years & $1=0.4 \%$ & $6=2.4 \%$ & \\
\hline Gender (Female/Male) & $(2=0.8 \% / 42=16.6)$ & $(115=45.5 / 94=37.2)$ & 0.000 \\
\hline \multicolumn{4}{|l|}{ BMI $\left(\mathrm{kg} / \mathrm{m}^{2}\right)$} \\
\hline Non-obese, non-overweight & $11=4.3 \%$ & $93=36.8 \%$ & \multirow{3}{*}{0.020} \\
\hline overweight & $18=7.1 \%$ & $62=24.5 \%$ & \\
\hline obese & $15=5.9 \%$ & $54=21.3 \%$ & \\
\hline \multicolumn{4}{|l|}{ LDL } \\
\hline High (160 - 189 mg/dl) & $3=6.8 \%$ & $1=0.5 \%$ & \multirow{2}{*}{0.001} \\
\hline Very high (>500 mg/dl) & $0=0.0 \%$ & $2=1.0 \%$ & \\
\hline \multicolumn{4}{|l|}{ Cholesterol } \\
\hline High (>240 mg/dl) & $3=6.8 \%$ & $5=2.4 \%$ & 0.350 \\
\hline \multicolumn{4}{|l|}{ HDL } \\
\hline $\operatorname{High}(<40 \mathrm{mg} / \mathrm{dl})$ & $29=65.9 \%$ & $128=61.2 \%$ & 0.104 \\
\hline \multicolumn{4}{|l|}{ TG } \\
\hline High (200 - 499 mg/dl) & $6=13.6 \%$ & $21=10.0 \%$ & \\
\hline Very high $(>500 \mathrm{mg} / \mathrm{dl})$ & $6=13.6 \%$ & $6=2.9 \%$ & 0.006 \\
\hline
\end{tabular}

Table 1 shows the sociodemographic and clinical characteristics of the participants. High-density lipoprotein (HDL); low-density lipoprotein (LDL); and (BMI): BODY mass index; is a value derived from the mass and height of an individual. The BMI is defined as the body mass divided by the square of the body height. 
in both groups were $39.0 \mathrm{mg} / \mathrm{dl}$ and $40.6 \mathrm{mg} / \mathrm{dl}$, respectively). On the other hand, $\mathrm{LDL}$ levels were somewhat greater in CAD patients carrying $\mathrm{T}$ allele when compared to CAD patients who are GG homozygotes (the averages were 93.3 $\mathrm{mg} / \mathrm{dl}$ and $97.2 \mathrm{mg} / \mathrm{dl}$ for both groups, respectively). Although the analysis has shown near normal HDL levels, 15 CAD patients with GG genotype had borderline high HDL levels while only one $\mathrm{CAD}$ patient carrying $\mathrm{T}$ allele has showed a similar value (P-value $>0.00$ ). See Figure 2 .

Upon the analysis of the results, most of CAD patients in the study displayed the WT allele. Only three patients showed the T allele including two patients who are heterozygous for the $\mathrm{T}$ allele and one CAD patients who is a homozygous for the $\mathrm{T}$ allele. One of the $\mathrm{T}$ allele carriers was assigned as a control while the remaining two patients were assigned as cases. See Table 2.

\subsection{Relationship between T Allele and Cholesterol Levels}

Two of the $\mathrm{T}$ allele patients were on Atorvastatin, a medication that lower cholesterol levels. These two patients have showed lower cholesterol levels than the GT carrier who was not on atorvastatin (cholesterol levels in patients with GT and TT alleles were $111 \mathrm{mg} / \mathrm{dl}$ and $134 \mathrm{mg} / \mathrm{dl}$, respectively while the levels in the third $\mathrm{T}$ allele patient was $258 \mathrm{mg} / \mathrm{dl}$ ). Regarding to CAD patients carrying the wildtype allele, their cholesterol plasma levels varied from normal to high (67

Table 2. Genotyping and allele frequencies for the participants cases.

\begin{tabular}{cccc}
\hline & GG n (\%) & GT n (\%) & TT n (\%) \\
\hline CAD & $42(16.6 \%)$ & $1(0.4 \%)$ & $1(0.4 \%)$ \\
NO CAD & $208(82.2 \%)$ & $1(0.4 \%)$ & $0(0.0 \%)$ \\
\hline
\end{tabular}

Table 2 patients and non separated by APOA5 genotype. The wildtype represents GG allele while GT and TT alleles indicate the presence of c.553G $>$ T. coronary artery disease (CAD).

\section{HDL average}

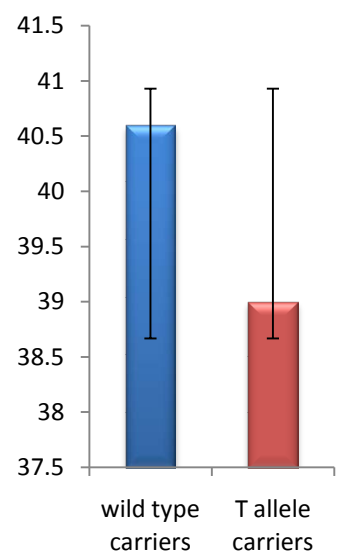

LDL average

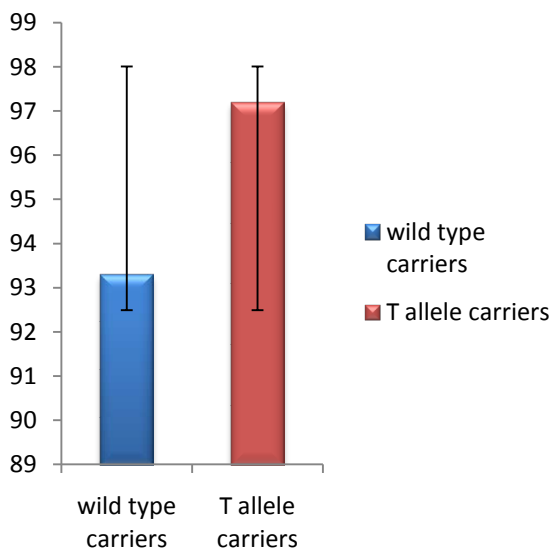

Figure 2. Comparison of LDL and HDL plasma levels in CAD patients carrying the wild type allele and patients with the T allele. Both groups showed similar levels of both LDL and HDL. However, patients with the wild type allele have shown slightly better results than the other group of patients. 
$\mathrm{mg} / \mathrm{dl}$ to $282 \mathrm{mg} / \mathrm{dl}$ ), and none of them were taking atorvastatin. However, the comparison between $\mathrm{T}$ allele patients and normal patients indicated that CAD patients carrying $\mathrm{T}$ allele had higher cholesterol levels than CAD patients who do not have the mutation in apoA5. The average of cholesterol levels in both groups: were $168 \mathrm{mg} / \mathrm{dl}$ for the first group and $155 \mathrm{mg} / \mathrm{dl}$ for the second). See Figure 3.

\subsection{The Relationship between T Allele Variant and Triglycerides Levels}

CAD patients carrying the $\mathrm{T}$ allele and are on atorvastatin had lower TG levels than GT heterozygotes patient who was not on the same drug. The patient who has GT allele had higher TG levels than the patient who is homozygotes to the variant (the TG levels for the three patients were $277 \mathrm{mg} / \mathrm{dl}, 170 \mathrm{mg} / \mathrm{dl}$ and 71 $\mathrm{mg} / \mathrm{dl}$ ). On the other hand, TG levels in CAD patients who are GG homozygotes varied from $22 \mathrm{mg} / \mathrm{dl}$ to $291 \mathrm{mg} / \mathrm{dl}$. The results have shown a strong correlation between $\mathrm{BMI}$ and CAD occurrence in patients involved in this study. CAD patients showed a higher BMI than the control group. According to their BMI results, about $[(24.7 \% \mathrm{n}=91 ; 10 \% \mathrm{n}=37) ;(15.4 \% \mathrm{n}=57 ; 6.2 \% \mathrm{n}=23) ;(6.2 \% \mathrm{n}=$ $23 ; 4.6 \% \mathrm{n}=17) ;(2.2 \% \mathrm{n}=8 ; 4.9 \% \mathrm{n}=18)]$ of CAD cases were characterized as overweight, obese I, obese II and obese III respectively (P-value $=0.000)$. Among CAD patients, $\mathrm{T}$ allele carriers have the highest BMI compared to others. They have, also, showed higher lipid profile results than patients in the control group. See Figure 4.

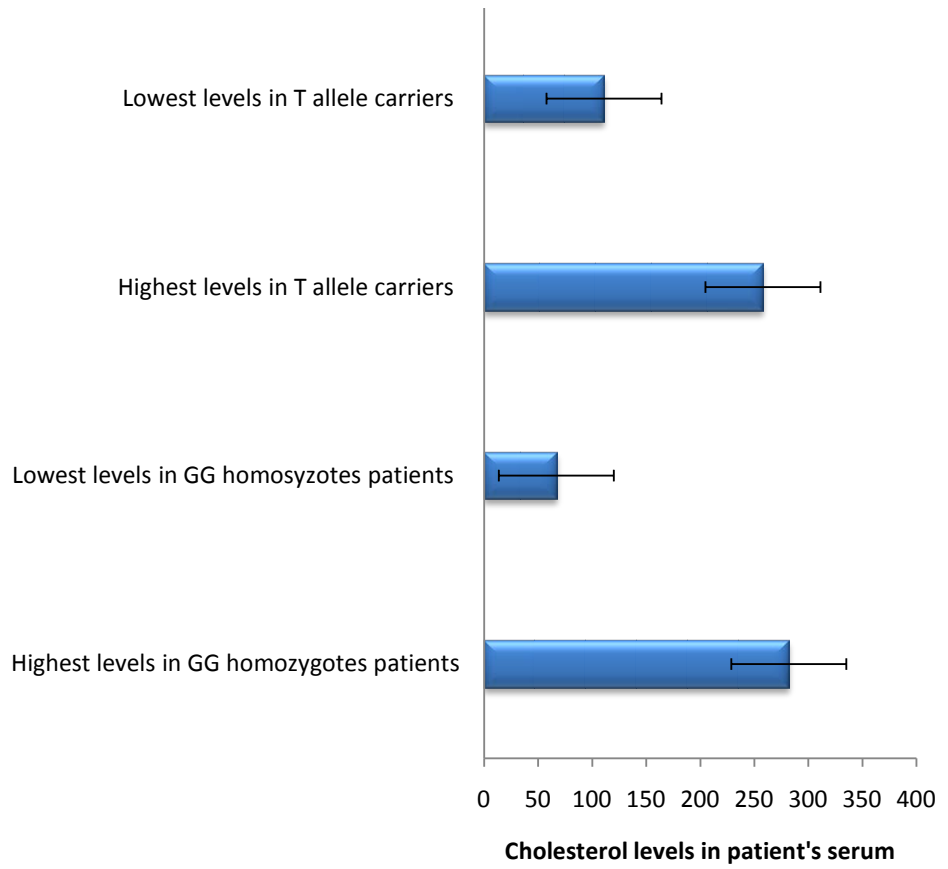

Figure 3. The range of cholesterol levels in CAD patients who have the wild type allele and other patients with the T allele. This chart shows the highest cholesterol levels in both groups of CAD patients. Also, it shows the lowest cholesterol levels in both groups, and the comparison between them. 


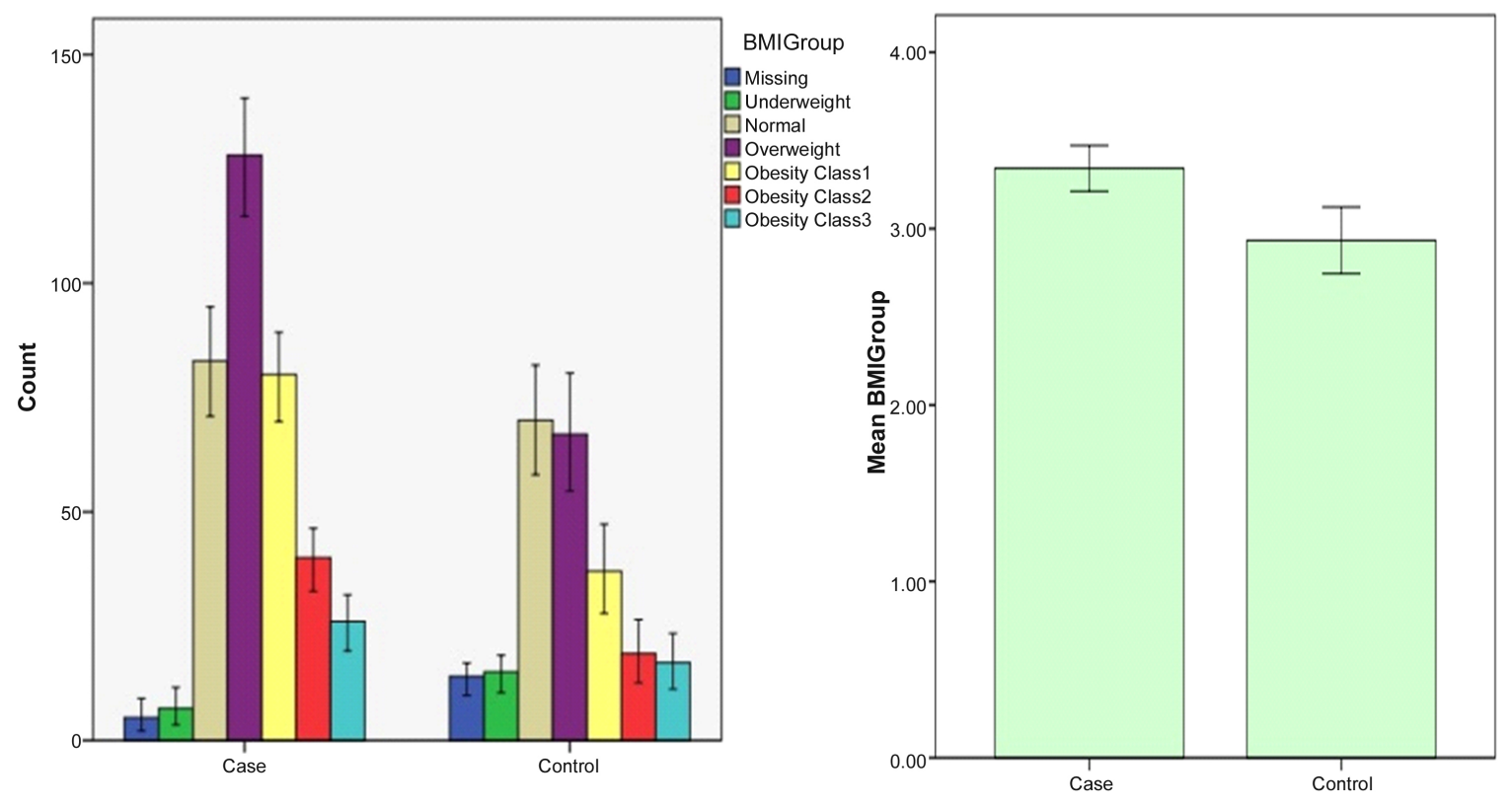

Figure 4. Comparison of BMI between CAD patients and the control group. This graph shows that CAD patients scored higher BMI measurements than normal subjects.

\section{Discussion}

Lipids are essential components in living organisms. They are usually soluble in organic solvents, but not in water. In human body, lipids are found in different forms such as triglycerides, lipoproteins, include LDL and HDL, and cholesterol [9]. Abnormal modifications of body lipids could cause mortality through the development of deadly diseases such as CVD. These alterations might occur due to genetic or environmental factors. Mutations in APOA5 gene have been associated with changes in the levels of blood lipids [10]; [11]. Recently, a new variant of APOA5, G162C (corresponding to c.553G $>$ T), has been discovered, and studies are being conducted to better understand the effects of this variant [12]. The purpose of this study is to examine the effects of the variant c.553G $>\mathrm{T}$ on TG, cholesterol, LDL and HDL levels.

Only 3 out of $280 \mathrm{CAD}$ patients had the T allele which indicates a remarkably lower frequency of this variant in general population. This results was, also, seen in Chinese and Chinese Taiwanese where the frequency of c.553G $>$ T presence is less than $8 \%$ in each populations. Although there were variations in LDL and HDL levels between CAD patients carrying the wildtype allele and patients who have $\mathrm{T}$ allele, none of them have any significant impacts. Therefore, it is can be concluded that $\mathrm{T}$ allele have no effects on LDL and HDL levels. This conclusion is similar to findings from another study. Tang et al. did not detect a relevance between c.553G $>$ T polymorphism and HDL-C and LDL-C levels [13]. The same interpretation was observed regarding to cholesterol levels. The results from this study did not detected any remarkable variations in cholesterol levels in CAD patients carrying the wildtype allele and other patients who are carrying c.553G $>\mathrm{T}$ polymorphism. This finding is similar to the results from another 
study that has declined any associations between $\mathrm{T}$ allele and changes in cholesterol levels [11]. Nevertheless, TG levels were higher in CAD patients with the wildtype than $\mathrm{CAD}$ patients who have the $\mathrm{T}$ allele. This result contradicts with the findings from meta-analysis of case-control studies that were performed on Asian population. With the comparison between APOA5 c.553T carriers and normal subjects in the study, GG carriers displayed lower levels of triglycerides than T allele carriers [14]. Another study that was done on Han population of Xinjiang in China showed that TG levels were different between CHD patients and control group depending on the presence or absence of the T allele. Patients who are APOA5 c.553T carriers presented higher levels of TG in both CHD and control groups [15]. This conflict between previous studies and the results from this study could be explained by the fact that CAD patients who are carriers of $\mathrm{T}$ allele were on atorvastatin. As presented by the results of this study, obesity is associated with CAD occurrence which confirms the outcomes of other studies that suggest that obesity is one of the major risk factors of CAD [16] [17]. In addition, the presence of $\mathrm{T}$ allele is more associated to obesity comparing to wild type carriers according to their BMI results.

\section{Conclusion}

In conclusion, the current study showed that the presence of c.553T variant in APOA5 has no effects on HDL and LDL serum levels. Although two of CAD patients who are APOA5 c.553T carriers were on atorvastatin, cholesterol levels did not vary between $\mathrm{T}$ allele carriers and GG genotype carriers. Interestingly, TG levels were higher in wildtype CAD patients than CAD patients who carry $\mathrm{T}$ allele and were on atorvastatin.

\section{Acknowledgements}

The authors would like to thank the Deanship of Scientific Research at Umm Al-Qura University for the continuous support. This work was supported financially by the Deanship of Scientific Research at Umm Al-Qura University to Dr. Neda Bogari (Grant Code: .15-MED-3-1-0062).

We all are deeply appreciated for Mr. Abdulmonim Gowda, and Mr Soud Abdulraof A. Khogeer, Mr Yamin Yaqoub Alsulimani, Dr Elaf Almatrouk, Dr Enas Alharthi, Dr Saad Alghamdi, Dr Khalid Faruqui, Mr Hussain Banni, Mr Sami Kalantan, Mr Mustafa N Bogari, and Mr Ehab Melibary.

\section{Conflicts of Interest}

The authors declare that they have no competing interests in relation to the work described.

\section{References}

[1] Vasunilashorn, S., et al. (2010) Blood Lipids, Infection, and Inflammatory Markers in the Tsimane of Bolivia. American Journal of Human Biology, 22, 731-740. 
https://doi.org/10.1002/ajhb.21074

[2] Zaret, B.L., et al. (1992) Yale University School of Medicine Heart Book. William Morrow and Co., New York.

[3] Fulks, M., Stout, R.L. and Dolan, V.F. (2009) Association of Cholesterol, LDL, HDL, Cholesterol/ HDL and Triglyceride with All-Cause Mortality in Life Insurance Applicants. Journal of Insurance Medicine, 41, 244-253.

[4] Nordestgaard, B.G. and Varbo, A. (2014) Triglycerides and Cardiovascular Disease. Lancet, 384, 626-635. https://doi.org/10.1016/S0140-6736(14)61177-6

[5] Cha, S., et al. (2014) Effects of Apolipoprotein A5 Haplotypes on the Ratio of Triglyceride to High-Density Lipoprotein Cholesterol and the Risk for Metabolic Syndrome in Koreans. Lipids in Health and Diseases, 13, 45.

https://doi.org/10.1186/1476-511X-13-45

[6] Vaessen, S.F., et al. (2006) Apolipoprotein A-V, Triglycerides and Risk of Coronary Artery Disease: The Prospective Epic-Norfolk Population Study. Journal of Lipid Research, 47, 2064-2070. https://doi.org/10.1194/jlr.M600233-JLR200

[7] Kao, J.T., et al. (2003) A Novel Genetic Variant in the Apolipoprotein A5 Gene Is Associated with Hypertriglyceridemia. Human Molecular Genetics, 12, 2533-2539. https://doi.org/10.1093/hmg/ddg255

[8] Zaki, M. and Amr, K. (2014) Apolipoprotein A5 T-1131C Variant and Risk for Metabolic Syndrome in Obese Adolescents. Gene, 534, 44-47.

https://doi.org/10.1016/j.gene.2013.10.032

[9] Crook, M. (2012) Clinical Biochemistry \& Metabolic Medicine. Hodder Arnold, London, New York.

[10] Hishida, A., et al. (2014) Polymorphisms of Genes Involved in Lipid Metabolism and Risk of Chronic Kidney Disease in Japanese-Cross-Sectional Data from the J-MICC Study. Lipids in Health and Diseases, 13, 162. https://doi.org/10.1186/1476-511X-13-162

[11] Yin, R.-X., et al. (2011) Interactions of the Apolipoprotein A5 Gene Polymorphisms and Alcohol Consumption on Serum Lipid Levels. PLoS ONE, 6, e17954. https://doi.org/10.1371/journal.pone.0017954

[12] Zhou, J., et al. (2013) Apolipoprotein A5 Gene Variants and the Risk of Coronary Heart Disease: A Casecontrol Study and Metaanalysis. Molecular Medicine Reports, 8, 1175-1182. https://doi.org/10.3892/mmr.2013.1642

[13] Tang, Y., et al. (2006) A Genetic Variant c.553G \&gt; T in the Apolipoprotein A5 Gene Is Associated with an Increased Risk of Coronary Artery Disease and Altered Triglyceride Levels in a Chinese Population. Atherosclerosis, 185, 433-437. https://doi.org/10.1016/j.atherosclerosis.2005.06.026

[14] He, H., et al. (2016) The c.553G>T Genetic Variant of the APOA5 Gene and Altered Triglyceride Levels in the Asian Population: A Meta-Analysis of Case-Control Studies. Genetic Testing and Molecular Biomarkers, 20, 758-765. https://doi.org/10.1089/gtmb.2016.0047

[15] Yuan, S., et al. (2011) Association between Apolipoprotein A5 Gene Polymorphism and Coronary Heart Disease in the Han Population from Xinjiang. Zhonghua Liu Xing Bing Xue Za Zhi, 32, 51-54.

[16] Flint, A.J., et al. (2010) Excess Weight and the Risk of Incident Coronary Heart Disease among Men and Women. Obesity (Silver Spring, Md.), 18, 377-383.

https://doi.org/10.1038/oby.2009.223 
[17] Hajar, R. (2017) Risk Factors for Coronary Artery Disease: Historical Perspectives. Heart Views: The Official Journal of the Gulf Heart Association, 18, 109-114. https://doi.org/10.4103/HEARTVIEWS.HEARTVIEWS_106_17 